\title{
Acoustic indices applied to biodiversity monitoring in a Costa Rica dry tropical forest
}

\section{Original paper}

Article history:

Received: 29 September 2017

Accepted: 26 February 2018

Published: 26 April 2018

\section{Check for updates}

\section{*Correspondence:}

MIRI: mretamos@una.cr

\section{Peer review:}

Double blind

\section{Copyright:}

(c) 2018 Retamosa Izaguirre et al. () This is an open access article distributed under the Creative Commons Attribution Non Commercial License (CC-BY NC 4.0), which permits unrestricted use, distribution, and reproduction in any medium for noncommercial purposes only, provided the original work is properly cited and its authors credited.

\section{Keywords:}

soundscapes; soundscape ecology; acoustic indices; biodiversity; birds; dry tropical forest

\section{Citation:}

Retamosa Izaguirre M. I., Ramírez-Alán O., and De la O Castro J. (2018). Acoustic indices applied to biodiversity monitoring in a Costa Rica dry tropical forest. Journal of Ecoacoustics. 2: \#TNW2NP. https://doi.org/10.22261/JEA.TNW2NP
Mónica I. Retamosa Izaguirre ${ }^{1,{ }^{*},}$ Oscar Ramírez-Alán², Jorge De la O Castro ${ }^{2}$

${ }^{1}$ Universidad Nacional, Apartado 1350-3000, Heredia, Costa Rica

${ }^{2}$ Universidad Nacional, Apartado 86-3000, Heredia, Costa Rica

\begin{abstract}
Standardized methods for biodiversity monitoring are needed to evaluate conservation efforts. Acoustic indices are used in biodiversity assessments, but need to be compared to traditional wildlife methods. This work was conducted in the Santa Rosa National Park between June and November, 2015. We installed recorders and conducted bird point counts in twelve sampling sites. We compared acoustic indices (Acoustic Evenness Index [AEI], Acoustic Diversity Index [ADI], Acoustic Complexity Index $[\mathrm{ACl}]$, Bioacoustic Index [BIO], Normalized Difference Soundscape Index [NDSI], Total Entropy [TE], Median Amplitude Envelope [MAE], Number of peaks [NP]) with indices from bird point counts (Bird Abundance, Bird Richness, Bird Diversity and Bird Evenness), and discuss the utility of acoustic indices as indicators for biodiversity monitoring in tropical forests. ADI, ACl, $\mathrm{BIO}$ and TE presented a similar temporal pattern peaking between 5 am and 6 am; and an additional peak at 5 pm, except for $\mathrm{ACl}$. These patterns were consistent with the daily biological rhythms. $\mathrm{AEI}, \mathrm{ACl}, \mathrm{BIO}$ and Bird Abundance were related to characteristics of younger forests (lower percentage of canopy cover) but NP, ADI, TE, Bird Diversity and Bird Evenness were related to characteristics of older forests (higher percentage of canopy cover and a lower number of patches). $\mathrm{ACl}$ was positively correlated to Bird Abundance and NP was positively correlated to Bird Diversity. ACl reflects biological activity, but not necessarily a more diverse bird community in this study area. This might be an indication of a strong acoustic competition, or several highly dominant bird species in younger forests. Furthermore, acoustic communities in tropical forests commonly include insects (cicadas) and frogs, which might affect resulting acoustic indices. A variety of methods are probably needed to thoroughly assess biodiversity. However, a combination of indices such as $\mathrm{ACl}$ and NP might be considered to monitor trends in abundance and diversity of birds in dry forests.
\end{abstract}




\section{Introduction}

Standardized and long-term methods for monitoring biodiversity are important and necessary to assess species response to global change and effectiveness of conservation efforts (Klingbeil and Willig, 2015). One of the major challenges in conservation ecology and biology, however, is assessment of biodiversity through effective monitoring techniques that span wide spatial and temporal scales (Depraetere et al., 2012). These monitoring programs including observing, locating, classifying and counting animals on a site are critical to: a) understand the state and trends of biodiversity, b) identify vulnerable and endangered species, c) assess the impact of human activity on ecosystems, and d) track invasive species and parasites, among others (Lee et al., 2008; Marsh and Trenham, 2008). However, they have a limited space-time scale and require considerable human and logistical resources.

Interpretation of sounds has been traditionally used to monitor vocalizing organisms. Conservation biology research has used recordings of wildlife vocalizations because they are efficient at confirming species presence, especially in environments with reduced visibility, such as tropical forests, aquatic systems and for studying nocturnal species (Farnsworth and Russell, 2007; Mennill and Vehrencamp, 2008; Bardeli et al., 2010; Odom and Mennill, 2010; Cugler et al., 2011). The acoustic information contained in these recordings can provide information on the ecology of vocalizing organisms and their habitats, including their diversity and abundance, as well as phenological events such as seasonal arrivals, breeding periods, and reproductive behavior (Gage et al., 2015).

Advances in acoustic sensor networks have allowed expansion of collection of acoustic signals in natural areas on a large scale and in an automated way (Porter et al., 2005; Aide et al., 2013; Ospina et al., 2013). Through the systematic and synchronous collection of acoustic data in multiple locations, combined with auxiliary data of light, temperature and humidity, a large volume of valuable ecological information has been produced (Gage et al., 2015). This promising acoustic tool provides the capacity to extend the spatio-temporal scale of biological sampling and to perform analyses of large volumes of information (Armitage and Ober, 2010; Bardeli et al., 2010; Caycedo-Rosales et al., 2013).

The acoustic data of an animal community are generally analyzed using three approaches: a) species auditory identification in recordings by an expert, b) species identification using automatic recognition on recordings, and c) development of global acoustic measurements without need for species identification (Gasc et al., 2013a; Sueur et al., 2014). The auditory identification of vocalizing individuals requires a high level of proficiency and can be performed only by experts (Dickinson et al., 2010) or by automated classification processes (Acevedo et al., 2009; Han et al., 2011). Both approaches are difficult to apply due to overlap of vocalizations observed in diverse acoustic communities (Gasc et al., 2013a).

Massive acoustic data need to be handled and analyzed with efficient acoustic tools (Sueur et al., 2014). Ecological research has traditionally used indices that describe with a single value the ecological complexity at the scale of community or landscape (Mason et al., 2008). The requirement for acoustic tools has led to the concomitant development of ecological indices based on acoustic data that can be used for biodiversity assessments, community dynamics research and landscape patterns (Sueur et al., 2014).

In spite of the variety of acoustic indices, only a few studies have assessed their efficacy (Mammides et al., 2017). Some of them have focused on simulated communities; for example Depraetere et al. (2012) reported an increase in the Entropy Index based on recorded frequencies with the number of species, and Sueur et al. (2008b) found an inverse correlation between an Index of Dissimilarity based on variations of frequencies collected and the number of species shared between two simulated communities. According to Gasc et al. (2013a), community-wide acoustic diversity indices revealed phylogenetic diversity and functional species diversity in a theoretical study of birds.

Other studies have compared acoustic indices with species diversity indices obtained by manually or automatically inspecting field recordings. Farina et al. (2011) and Pieretti et al. (2011) showed the capacity of the Acoustic Complexity Index (ACI) to describe the complexity of bird soundscapes in northern Italy. Depraetere et al. (2012) found the Acoustic Richness index retrieved expected bird richness values in a temperate French forest. Besides, Towsey et al. (2014) found that acoustic indices 
such as temporal entropy (Ht), Spectral Entropy (Hs) and ACI were useful indicators of bioacoustic activity in general, mainly species diversity, in an Australian bush land. Furthermore, Machado et al. (2017) found that the Acoustic Diversity Index (ADI) was significantly correlated to the number of bird species in the savannas from Central Brazil.

However, validation of acoustic indices exists mostly in temperate ecosystems. Because tropical environments contain higher levels of diversity (Rodrigues et al., 2014; Pieretti et al., 2015), their validation is essential in tropical environments (Trigg, 2015). In addition, studies to date have focused on acoustic and species diversity indices obtained from recordings, but comparison with ecological data taken by traditional wildlife methods is not yet readily available. In southern China, Mammides et al. (2017) assessed performance of several acoustic indices by measuring its correlation to bird species richness and diversity estimated using point-count surveys. These authors found that although no index showed a very strong correlation with species richness or diversity, three indices (the acoustic entropy, acoustic diversity and acoustic evenness indices) performed consistently better, showing moderate correlations.

According to Sueur et al. (2014), acoustic indices estimating within-group diversity can be divided into three categories, depending on what they measure, either sound energy, level of complexity in terms of time, frequency and/or amplitude, or the proportion of different components of a soundscape. These authors postulated that "complexity indices" are based on the assumption that the acoustic output of a community or a landscape will increase in complexity with the number of singing individuals and species. Consequently, an index that captures the heterogeneity of sounds should then give a proxy of animal acoustic activity. Based on this assumption, the objective of in this article was to compare acoustic indices with indices derived from bird point counts and discuss the utility of acoustic indices as an alternative strategy to monitor biodiversity in tropical forests. We specifically hypothesized that indices measuring acoustic diversity, heterogeneity or complexity should reflect bird diversity assessed by traditional point count surveys. Furthermore, we expected higher acoustic diversity, heterogeneity or complexity, as well as higher bird diversity in older and more preserved forests, which would result in noticeable spatial patterns in the study area. In addition, we expected temporal patterns in acoustic and diversity indices, with biological activity peaks at dawn and dusk.

\section{Study area}

The study was conducted in the Santa Rosa National Park (SRNP), Guanacaste Conservation Area from Costa Rica (Figure 1). The park is located southwest of the Santa Elena Peninsula, in the NorthPacific region of Costa Rica $\left(10^{\circ} 53 \mathrm{~N}, 85^{\circ} 46 \mathrm{~W}\right)$ and includes terrestrial and marine-coastal ecosystems. It encompasses $850.65 \mathrm{~km}^{2}$; of which $463.91 \mathrm{~km}^{2}$ corresponds to protected marine areas (Salas et al., 2012).

The SRNP is located within the North Pacific Climate Region, specifically in the central subregion, in the Guanacaste plain. In this subregion severity of the climate prevails with prolonged dry periods. It belongs to the Pacific precipitation regime, characterized by the presence of two well-defined periods, i.e., dry and rainy. The annual rainfall regime is denominated drought with a precipitation between 1,100 and 1,500 $\mathrm{mm}$ (Solano and Villalobos, 2001).

The region has a dry season of five to seven months, usually from December to mid-May. During the rainy season (mid-May to November) precipitation can vary between 800 and 2,800 $\mathrm{mm}$ with an annual average of $1,500 \mathrm{~mm}$. An "Indian summer" or dry spell occurs during the rainy season of up to six weeks between July and August (Janzen, 2004). The temperature varies between 26 and $36^{\circ} \mathrm{C}$ during the day and 18 to $22^{\circ} \mathrm{C}$ at night. Strong winds come from the northeast during the first half of the dry season (Janzen, 2004).

According to the Holdridge life zone system, SRNP presents Pre-montane Wet Forest and Tropical Dry Forest (Bolaños et al., 2005). Most plant species are deciduous with short, coarse, and slightly dense shafts, as well as a few epiphytes (Solano and Villalobos, 2001). The understory is relatively open, especially during the dry season, when most shrubs lose their leaves (Graham et al., 2016). 


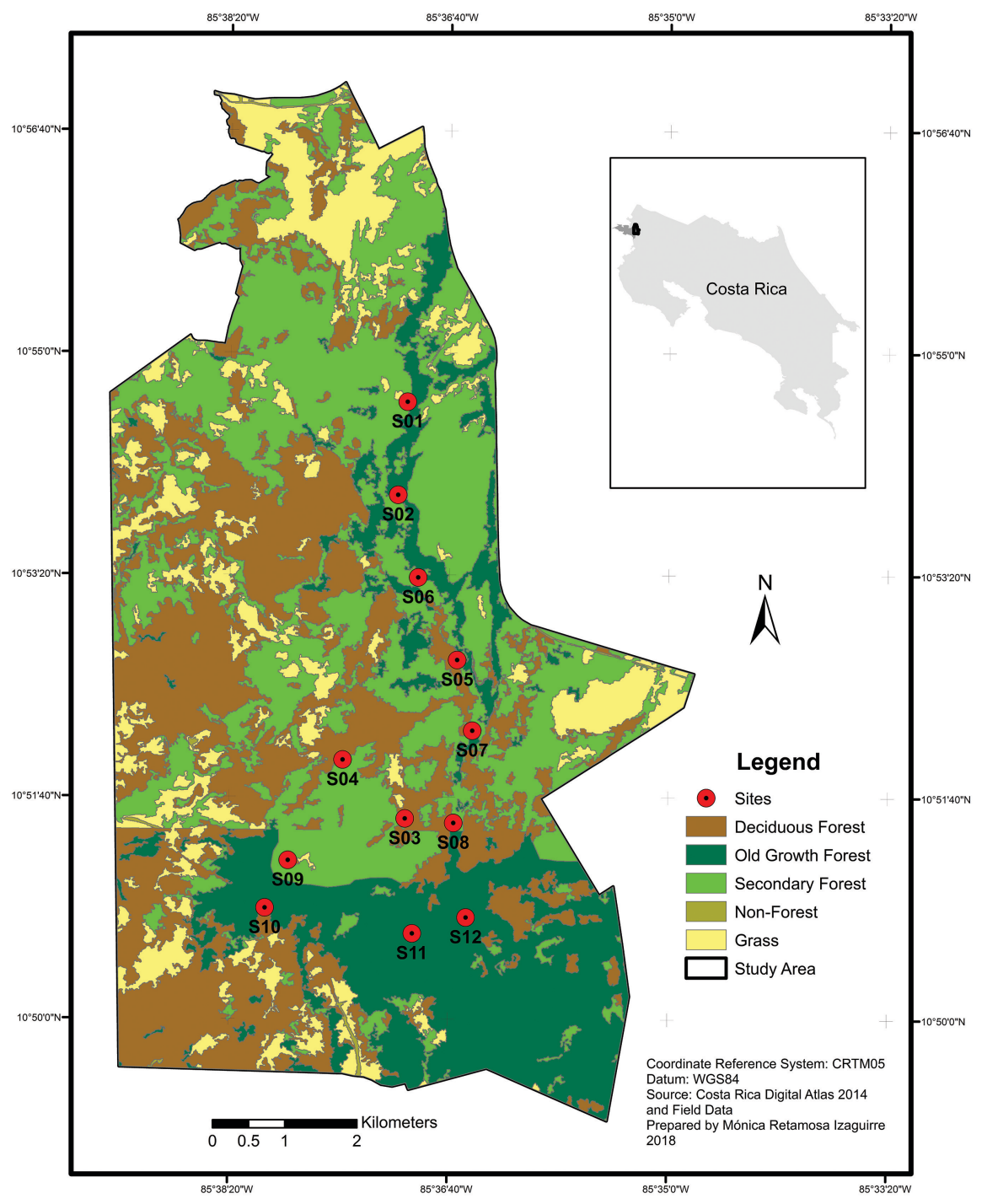

Figure 1. Study area in Santa Rosa National Park, Costa Rica.

The SRNP dry forest is floristically more diverse compared to the dry tropical forest of other wild protected areas in Central America (Gillespie et al., 2000). It includes secondary forest in different regeneration states and mature forest older than 50 years with a canopy of $30 \mathrm{~m}$ of height in sites unaffected by the agriculture. At least 159 woody species have been reported in the SRNP. In addition, it is considered a mosaic since it includes other types of vegetation such as grasslands and dry oak forest communities (Kalacska et al., 2004; Powers et al., 2009; Carvajal-Vanegas and Calvo-Alvarado, 2013). Dominant bird species of the dry forest include: Chiroxiphia linearis, Pachyramphus aglaiae, Thamnophilus doliatus, Thryophilus pleurostictus, among others. These species are characterized by emitting loud vocalizations and calls at different times of the day (Stiles and Skutch, 2007).

Tropical dry forest is a globally threatened ecosystem and is considered a high priority for conservation (Miles et al., 2006). In the province of Guanacaste, tropical dry forest restoration processes have been taken place since the 1980s, a as result of multiple socioeconomic factors and conservation policies (Calvo-Alvarado et al., 2009). The Guanacaste Conservation Area has contributed to tropical dry forest protection through regeneration of areas historically dedicated to extensive livestock and exposed to burning and cutting processes (Janzen, 2000). This study area was chosen because it contains representative samples of the most fragile forests in the country and potentially threatened by the 
negative impacts of climate change, and therefore requires long-term monitoring programs for their effective conservation.

\section{Materials and methods}

\section{Characterization of the study area and sampling sites}

We surveyed 12 sampling sites in SRNP between June and November of 2015; this time period corresponded to the wet climatic season (Figure 1). Each sampling site consisted of a 1,000 m transect; transects were located $500 \mathrm{~m}$ apart from each other. To characterize the landscape, we used a buffer area of $500 \mathrm{~m}$ around the central location of each sampling site. In this area, the following landscape metrics were calculated using the Patch Analyst extension (Rempel et al., 2012) for ArcGIS (ESRI, 2016): Shannon Diversity Index (SDI), Number of Patches (NumP), Mean Patch Edge (MPE), Mean Patch Size (MPS) and Mean Perimeter/Area Ratio (MPAR). In addition, we performed a spatial trend analysis and interpolation procedures with each landscape index using the Geostatistical Analyst extension for ArcGIS (ESRI, 2016).

We also sampled the vegetation structure in sampling sites using plots of $20 \mathrm{~m}$ radius. In each plot we counted and measured the Diameter at Breast Height (DBH) of every tree with more than $10 \mathrm{~cm}$ of DBH. With this data we obtained the total number of trees (NTREES) and the total basal area of trees (BASALAREA) for each plot. In addition, all shrubs with less than $10 \mathrm{~cm}$ of DBH were counted in a $5 \mathrm{~m}$ radius subplot (UNDERSTORY). We finally estimated the canopy cover in four points at each plot with a forest densiometer and the average value for each plot was obtained (CANOPY).

\section{Characterization of soundscapes and bird communities}

On each of the 12 sampling sites, we installed five Song Meter Digital Field Recorder Plus (SM2+; Wildlife Acoustics Inc.) recorders, spaced every $200 \mathrm{~m}$. To determine spacing distance between recorders, a fixed source was placed to reproduce a sound (the recorded song of a bird) and then recordings were made at distances from that source ranging from $100 \mathrm{~m}$ to $500 \mathrm{~m}$. Later, these recordings were analyzed auditively and their spectrograms explored to choose the distance between recorders that allowed the independence in the collection of acoustic data. Two omnidirectional microphones were placed on each recorder, so recording was done through two channels, i.e., in stereo. The quality of digital audio was compact disc with a sampling rate or frequency rate of $44.1 \mathrm{kHz}$ and 16 bits resolution. The audio files were recorded in Microsoft Wave format (.wav). Audio files were stored on 64 GB Secure Digital High Capacity memory cards. At each recording site equipment was fixed to trees at a height of approximately $1.50 \mathrm{~m}$. Recorders were programmed to make continuous recordings during peaks of bird activity (4-6 am and 4-6 pm), and during 10 minutes every hour for the remainder of the day; and stayed at each recording site for two consecutive days.

To evaluate acoustic indices as indicators for biodiversity, specifically diversity, abundance and richness of birds, traditional methods of bird point counts were additionally performed. We conducted four periods of bird point counts at each recording site during the morning (6-9 am) and the afternoon (15-17 pm), periods where the maximum bird activity is usually recorded. Each counting period was performed for 6 minutes by the same observer throughout the study. With the bird data we obtained species richness (Bird Richness), mean abundance (Bird Abundance), Shannon diversity (Bird Diversity; Shannon and Weaver, 1964) and evenness (Bird Evenness; Pielou, 1984) for each sampling site.

Recordings were analyzed to obtain a series of acoustic indices:

1) "Acoustic Evenness Index" (AEI) is calculated by dividing the spectrogram into bins (default 10) and taking the proportion of the signals in each bin above a threshold (default $-50 \mathrm{dBFS}$ ). The AEI is the result of the Gini index applied to these bins (Villanueva-Rivera and Pijanowski, 2018); 2) "ADI" is calculated by dividing the spectrogram into bins (default 10) and taking the proportion of the signals in each bin above a threshold (default $-50 \mathrm{dBFS}$ ). The ADI is the result of the Shannon index applied to 
these bins (Villanueva-Rivera and Pijanowski, 2018); 3) “ACI” for each frequency bin over the entire one minute recording, calculates the average absolute fractional change in spectral amplitude from one spectrum to the next; ACI for the entire recording is the average over all frequency bins. The ACI is based on the observation that many biotic sounds, such as bird songs, are characterized by an intrinsic variability of intensities, while some types of human generated noise (such as car passing or airplane transit) exhibit very constant intensity values (Pieretti et al., 2011); 4) "Bioacoustics Index" (BIO) is calculated as the area under each curve including all frequency bands associated with the $\mathrm{dB}$ value that is greater than the minimum $\mathrm{dB}$ value for each curve. The area values are thus a function of both the sound level and the number of frequency bands used by the avifauna (Boelman et al., 2007); 5) "Normalized Difference Soundscape Index" (NDSI) estimates the level of anthropogenic disturbance on the soundscape by computing the ratio of human-generated (anthrophony) to biological (biophony) acoustic components found in field collected sound samples (Kasten et al., 2012); 6) "Total Entropy" (TE) function estimates the total entropy of a time wave. The entropy of a noisy signal will tend towards one whereas the entropy of a pure tone signal will tend towards cero (Sueur et al., 2008a); 7) Median Amplitude Envelope (MAE) function computes an acoustic index based on the median of the amplitude envelope (Depraetere et al., 2012); and 8) "Number of Peaks" (NP) is built by counting the number of major frequency peaks obtained on a mean spectrum. This index results from the assumption that spectral complexity of a sound can be assessed by the number of frequency bands occupied (Gasc et al., 2013b). In the case of ACI, ADI, AEI and BIO, filters with a minimum of 2,000 to a maximum frequency of $11,000 \mathrm{kHz}$ were used. The indices were calculated for the first minute of each recording.

For comparison of acoustic indices and bird point counts derived indices, we used the recordings corresponding to the time block used to perform the bird point counts, from 6-9 am and 15-17 pm. Otherwise, we present mean and standard deviation of acoustics indices, as well as graphic representation of indices for all sampling hours throughout the day.

We reviewed each recording (by listening and exploring frequency plots) for extreme values, either due to climatic conditions, mainly rain or very strong wind, or to other animal explosive vocalization behavior (by frogs or insects). When we verified these extreme conditions, we proceeded to eliminate the corresponding $1 \mathrm{~min}$ wav file.

\section{Data analysis}

We evaluated the distribution of acoustic indices by using boxplots to compare indices averages by time of the day and sampling site. To visually examine the spatial distribution and spatial patterns of both acoustics and point count derived indices, we created interpolated surfaces from indices for the study area. To further analyze these visual similarities, we created a sample of 60 random points for the study area, and extracted values from all interpolated surfaces for the location of these points. We finally run multiple correlation methods (Spearman correlation) to assess correlation between interpolated surfaces of all indices.

Also, we conducted generalized linear models (GLM; Gamma family and log link) for each acoustic index/bird point count derived index to further investigate influence of vegetation structure/landscape metrics on indices. In this case, we previously evaluated correlation among vegetation and landscape variables and used a reduced subset of non-correlated variables including four vegetation variables (NTREES, BASALAREA, UNDERSTORY and CANOPY) and three landscape metrics (NumP, MPE and MPAR). We ran separate models for each acoustic index and bird point count derived index, and considered a total of 28 models ( 9 with only vegetation structure variables, 6 with only landscape metrics, and 13 with both variables), and finally compared them with Akaike Information Criteria (AIC). Best model and models with a delta AIC less than 2 are shown. Finally, we compared acoustic indices and bird point count derived indices using multiple correlation methods (Spearman correlation) to evaluate the efficiency of acoustic indices to represent biodiversity of birds in a tropical dry forest. We also used Spearman correlation to evaluate correlation among acoustic indices.

All analyzes and plots were performed using the statistical language R (R Development Core Team, 2017). For calculation of acoustic indices, the following packages for R were used: "Soundecology" 
(Villanueva-Rivera and Pijanowski, 2018) and "Seewave" (Sueur et al., 2008a). We used BiodiversityR (Kindt, 2018) package for $\mathrm{R}$ to analyze bird data obtained from point counts. Spatial procedures were conducted using the Geostatistical Analyst extension for ArcGIS (ESRI, 2016).

\section{RESULTS}

\section{Characterization of the study area and bird communities}

In general, a trend in the spatial patterns was observed from northern to southern section of the study area. The southern part of the study area presented the lowest diversity and lower equity (or greater dominance) in the abundance of classes of vegetation cover, and represented the most continuous and well preserved forested area, where even the only evergreen patch of the park was found. At the center of the study area we observed greater landscape diversity and greater equity of classes of vegetation cover. This area presented secondary forest patches interspersed with riverine forest patches, although central-east areas exhibited a more advanced successional stage than central-western areas. In general, we also observed in this central area higher number of patches, higher amount of edges, and smaller patches (Figure 2).

A total of 101 bird species were recorded in point counts, corresponding to 14 orders and 32 families (Appendix 1). 80 species are resident, 4 have resident and migratory populations, 2 have resident reproductive and migratory populations, 13 are strictly migratory species and 2 are endemic residents. Tyrannidae was the most representative family with a total of 21 registered species. We also observed a tendency for higher values in indices derived from bird point counts in the morning than the afternoon (Table 1).

\section{Temporal distribution of acoustics indices}

ADI, ACI, BIO, TE acoustic indices presented a similar pattern with a peak between 5 and $6 \mathrm{am}$. All indices, except ACI, presented an additional peak at $5 \mathrm{pm}$. Moreover, these indices presented lower values at midday; commonly between $10 \mathrm{am}$ and $3 \mathrm{pm}$. AEI presented a pattern generally opposed to that of ADI, ACI, BIO and TE, and similar to MAE and NP. NDSI presented the lowest value at noon and the highest value at $5 \mathrm{pm}$ (Figure 3).

\section{Spatial distribution of acoustic and bird point count derived indices}

All acoustic indices showed variation across the sampling sites, which could respond, at least in part, to the presence of some extreme values. MAE showed less variation among all acoustic indices (Figure 4). From the visual examination of interpolated surfaces of acoustic indices and bird point counts derived indices, we observed that $\mathrm{ACI}, \mathrm{BIO}$ and bird abundance showed a highly similar spatial pattern in the study area. The same was found for NP, bird diversity and bird evenness; NDSI also approximated these three indices. In addition, TE and ADI showed a close spatial pattern. Other spatial similarities can be observed between MAE and AEI (Figure 5). All these visual spatial associations were supported by the correlation analysis $(p<0.05)$.

Most of the best GLM included vegetation variables (CANOPY and BASALAREA) and one landscape metric (NUMP, Table 2). Indices such as AEI, ACI, BIO and Bird Abundance were negatively related to percentage of canopy cover; while NP and Bird Evenness were positively related to percentage of canopy cover. On the other hand, AEI and MAE were positively related to the number of patches, while TE was negatively related to the number of patches. Finally, Bird Richness was negatively related to basal area, while Bird Diversity was positively related to basal area. NDSI presented a different behavior than other indices and was positively related to the number of trees. 


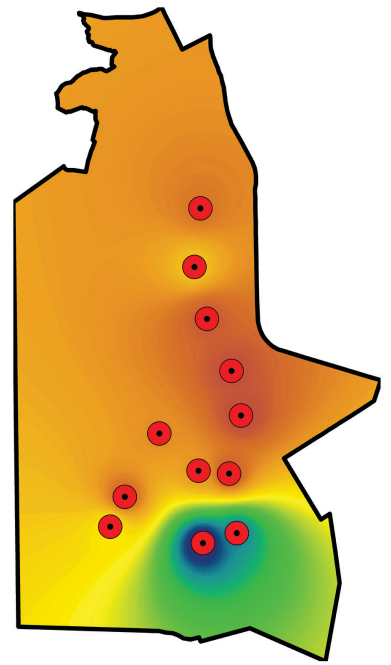

SDI

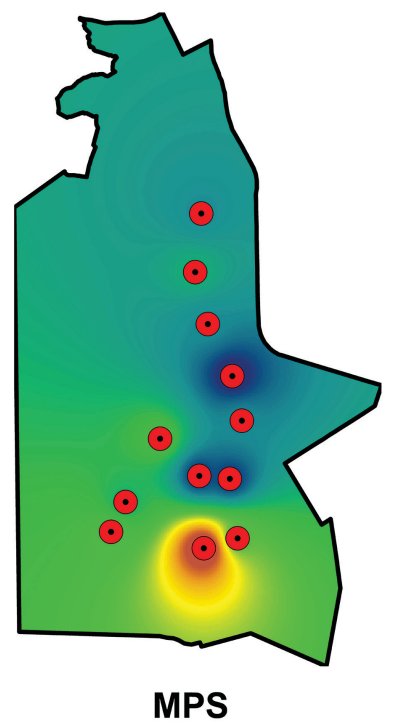

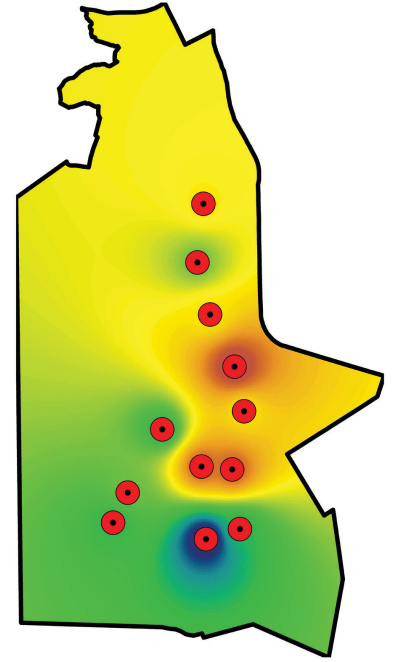

NumP

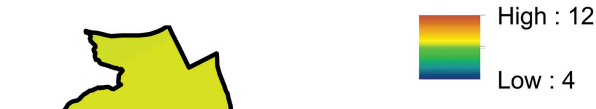

Surface of MPS

High : 19.622

Low : 6.543

\section{Surface of MPE}

High : 3706.6

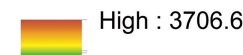

Low : 1284.7

Figure 2. Interpolated surfaces of landscape metrics in Santa Rosa National Park, Costa Rica.

SDI: landscape Shannon diversity, NumP: number of patches, MPE: mean patch edge, MPS: mean patch size and MPAR mean perimeter/area ratio. Warm and cold colors indicate higher and lower values of the interpolated index, respectively

\section{Comparison between acoustic indices and bird point count derived indices}

ACI was negatively correlated to Bird Diversity and Bird Richness (rho $=-0.7412, p=0.0082$, rho $=-0.6432, p=0.0240$, respectively), but positively correlated to Bird Abundance (rho = $-0.6059, p=0.0368$; Table 2). BIO and MAE also were negatively correlated to Bird Diversity (rho $=-0.6434, p=0.0279$, rho $=-0.5874, p=0.0488$, respectively); however, NP was positively correlated to Bird Diversity (rho $=0.6783, p=0.0188$ ). Finally, ADI was negatively correlated to Bird Abundance (rho $=-0.6444, p=0.0237$ ), nonetheless AEI was positively correlated to Bird Abundance (rho $=0.6130, p=0.0341)$ (Table 3).

On the other hand, analyzing the correlation among acoustic indices only, we found three groups of indices with an apparent similar behavior: 1) ADI, TE and NP; 2) AEI, MAE, ACI and BIO; and 3) NDSI. This last index was the least correlated to other indices (Table 4). 
Table 1. Mean of indices derived from bird point counts for sampling sites in the Santa Rosa National Park, Costa Rica.

\begin{tabular}{|c|c|c|c|c|}
\hline Site & Bird Richness & Bird Abundance & Bird Diversity & Bird Evenness \\
\hline S01 & 47 & 1.426 & 3.468 & 0.901 \\
\hline S02 & 35 & 1.257 & 3.257 & 0.916 \\
\hline S03 & 33 & 1.980 & 3.018 & 0.863 \\
\hline SO4 & 34 & 2.040 & 3.100 & 0.879 \\
\hline S05 & 29 & 1.168 & 3.084 & 0.916 \\
\hline S06 & 26 & 1.297 & 2.834 & 0.870 \\
\hline S07 & 33 & 1.218 & 3.242 & 0.927 \\
\hline S08 & 32 & 1.030 & 3.070 & 0.886 \\
\hline S09 & 34 & 1.010 & 3.260 & 0.925 \\
\hline S10 & 41 & 1.158 & 3.346 & 0.901 \\
\hline S11 & 37 & 1.168 & 3.290 & 0.911 \\
\hline S12 & 37 & 1.099 & 3.367 & 0.932 \\
\hline$\dot{X}$ Morning & 85 & 11.28 & 3.74 & 0.842 \\
\hline$\dot{X}$ Afternoon & 69 & 6.11 & 3.65 & 0.864 \\
\hline
\end{tabular}

\section{Discusion}

Acoustic indices such as ADI, ACI, BIO and TE presented a similar temporal pattern with a peak between 5 and $6 \mathrm{am}$; and an additional peak at $5 \mathrm{pm}$, except for ACI. These patterns were expected and consistent with the daily rhythms of bird activity. The dawn chorus is generally recognized as an acoustic peak time and has been widely reported in observational studies (Henwood and Fabrick, 1979; Berg et al., 2006). Other authors have found that acoustic diversity indices are capable of detecting these activity patterns, both in temperate (Depraetere et al., 2012) and in tropical environments (Rodrigues et al., 2014; Trigg, 2015). Hayes (2016) also found the ACI showed its highest value around $5.30 \mathrm{am}$ in the SRNP. However, this author found lowest values of ADI and TE at 6 $\mathrm{pm}$, while in the present study one of the higher values for both indices was found at $5 \mathrm{pm}$.

ACI might be representing acoustic patterns related to diurnal birds in the study area, which show an activity peak in the morning. On the other hand, the highest mean values of ADI, BIO and TE at $5 \mathrm{pm}$ might be attributed to other organisms in addition to birds. Rodrigues et al. (2014) mentioned that dawn chorus is a particular time of activity for diurnal birds and other times are dominated by cicadas and amphibians. Furthermore, it has been postulated that the entropy index is affected by sounds that cover a wide spectrum, such as cicadas (Sueur et al., 2008a), which show peaks of activity in hours of the afternoon Hayes (2016). Stanley et al. (2016) also found that cicadas produced an inhibitory effect on bird singing activity within the bandwidth of cicada calls; thus, insect noise appears to create a frequency-dependent constraint on the calling activity of birds, which might be overcome by temporal partitioning of acoustic space. In addition, we observed a tendency for higher values of indices derived from bird point counts in the morning compared to the afternoon, which might support this idea. 


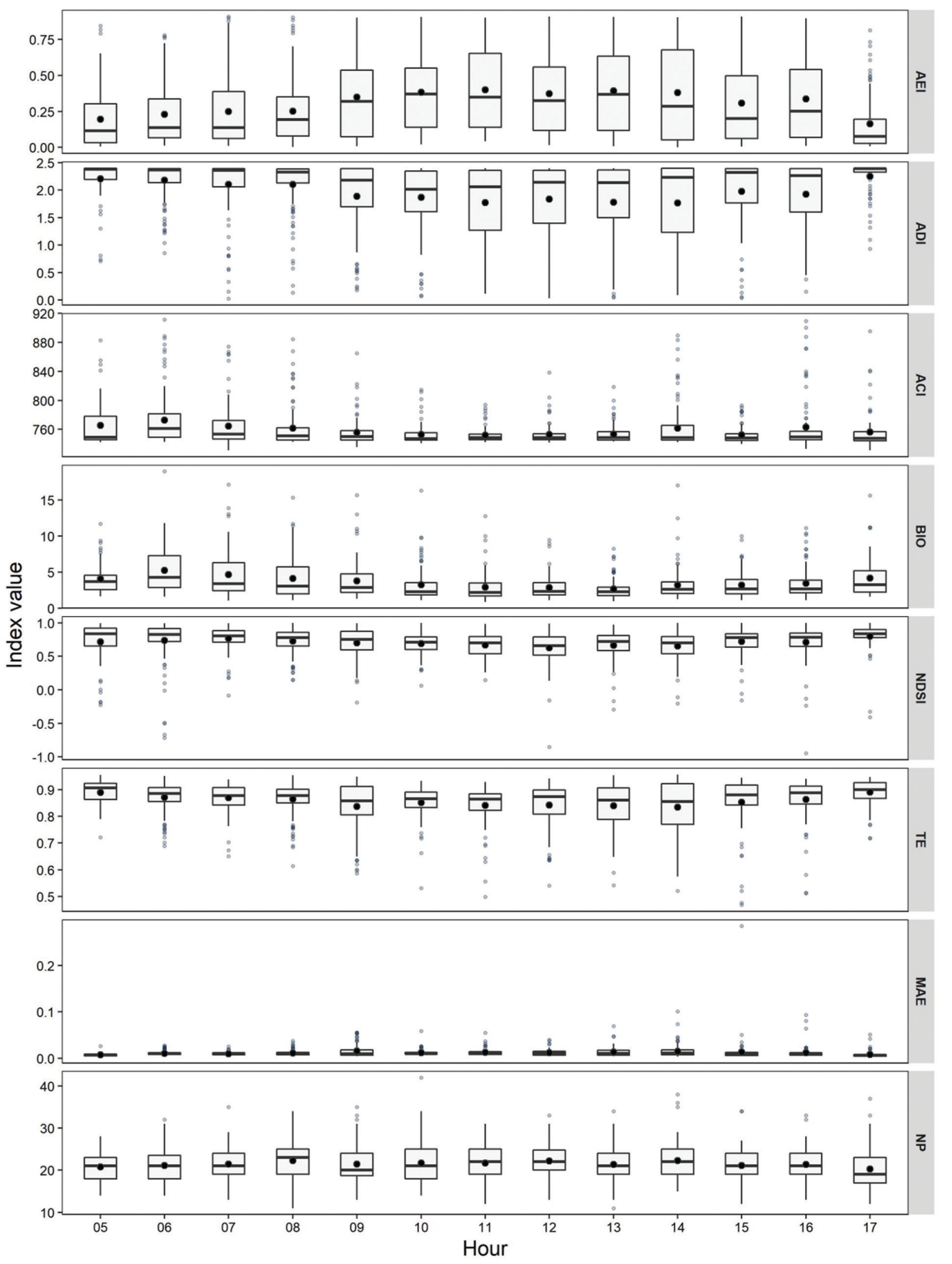

Figure 3. Acoustic indices distribution by time of the day (average $\pm 95 \% \mathrm{Cl}$ ) in the Santa Rosa National Park, Costa Rica.

AEl: Acoustic Evenness Index, ADI: Acoustic Diversity Index, ACl: Acoustic Complexity Index, BIO: Bioacoustic Index, NDSI: Normalized Difference Soundscape Index, TE: Total Entropy, MAE: Median Amplitude Envelope, NP: Number of Peaks. 

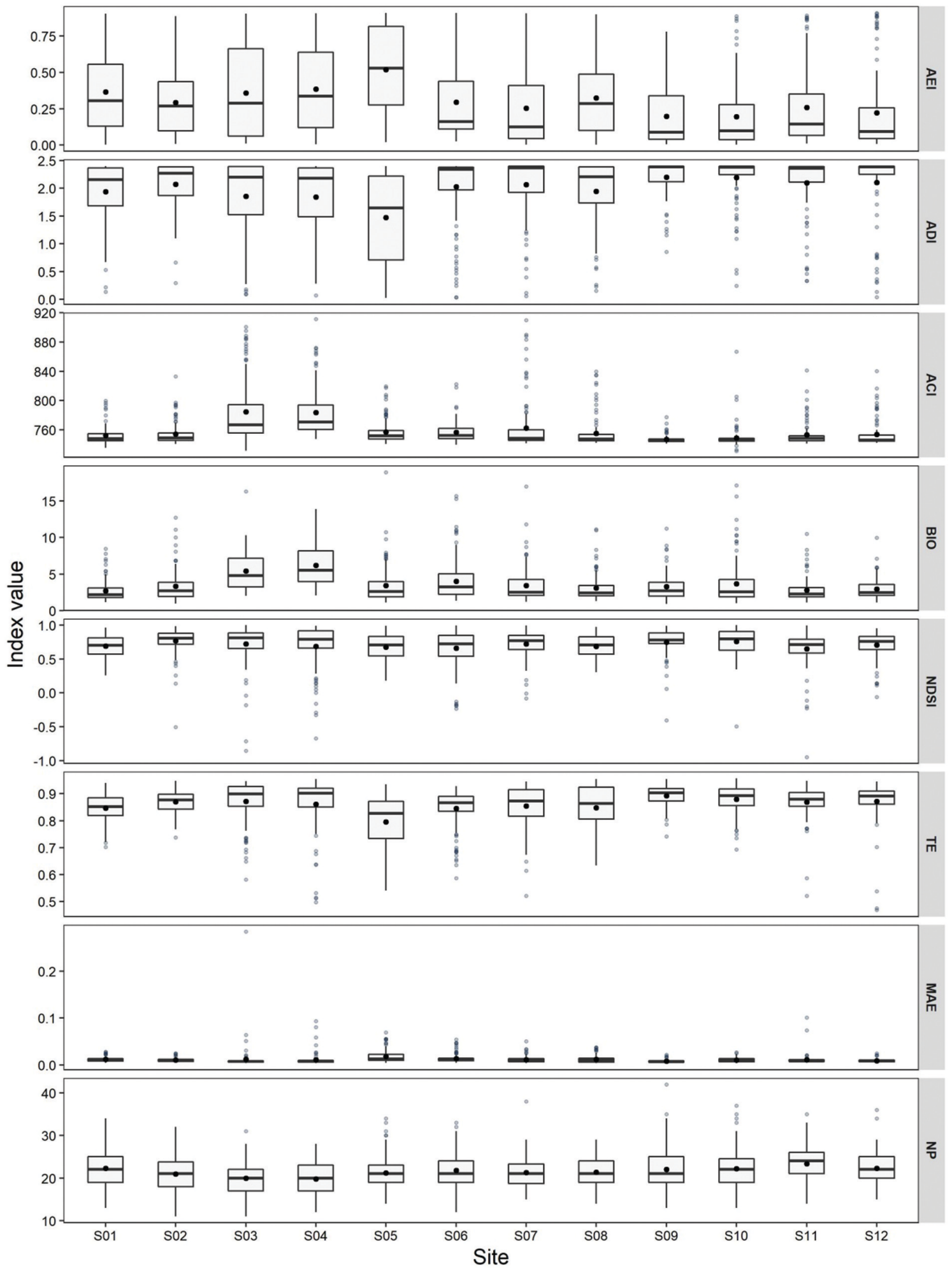

Figure 4. Acoustic indices distribution by sampling sites (average $\pm 95 \% \mathrm{Cl}$ ) in the Santa Rosa National Park, Costa Rica.

AEI: Acoustic Evenness Index, ADI: Acoustic Diversity Index, ACl: Acoustic Complexity Index, BIO: Bioacoustic Index, NDSI: Normalized Difference Soundscape Index, TE: Total Entropy, MAE: Median Amplitude Envelope, NP: Number of Peaks. 


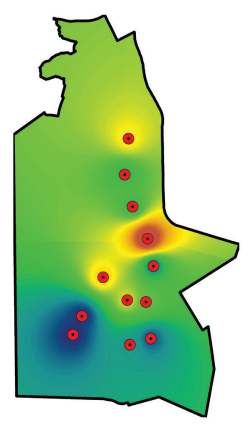

AEI

High : 0.5193

Low : 0.1962

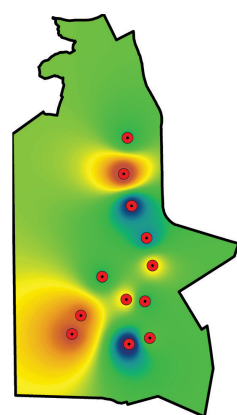

NDSI
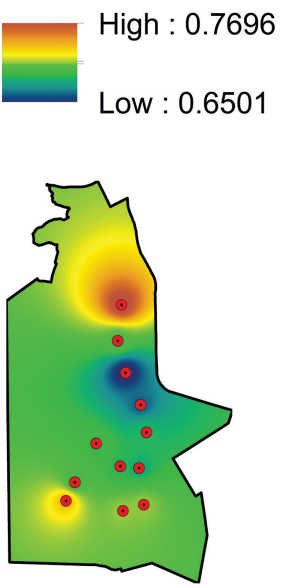

\section{B.Richness}

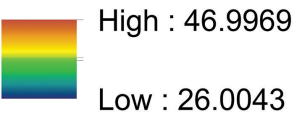

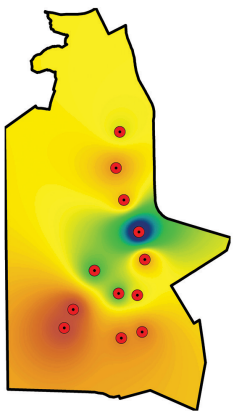

ADI
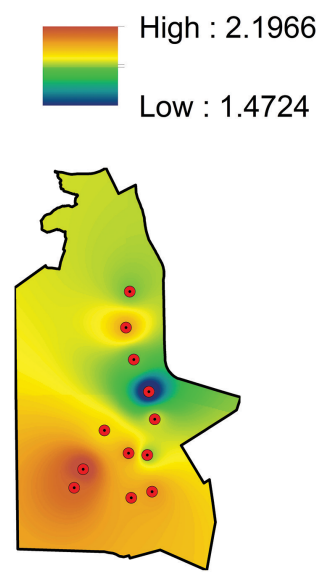

TE
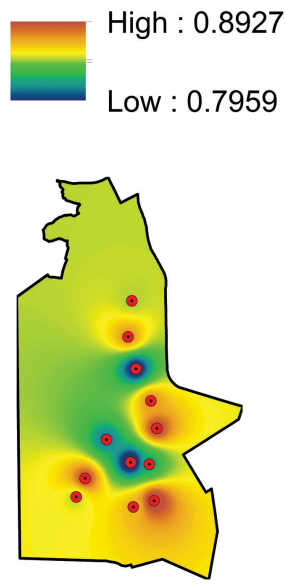

\section{B.Evenness}

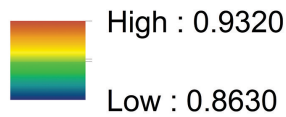

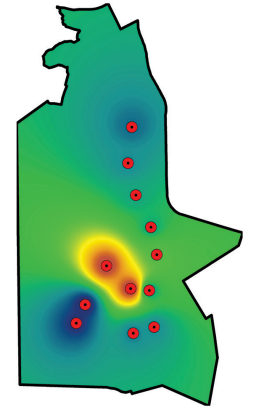

ACI
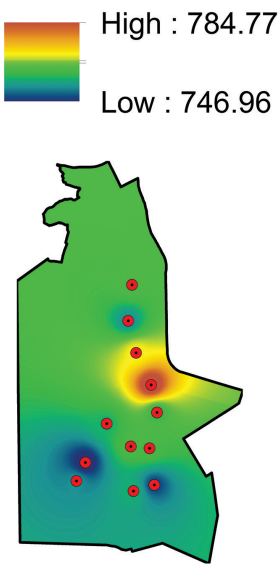

MAE
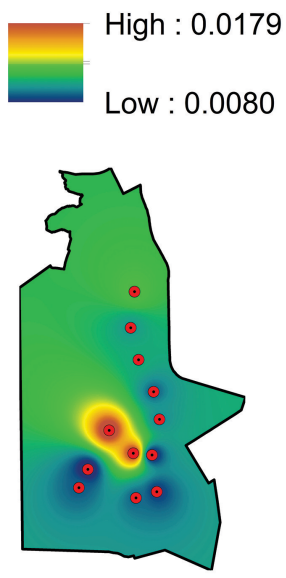

\section{B.Abundance}

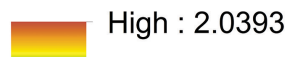

Low : 1.0102

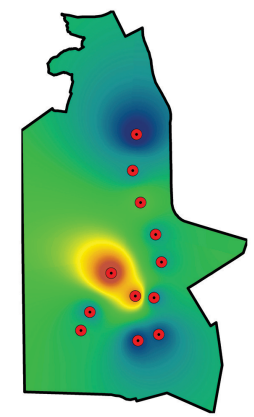

\section{BIO}
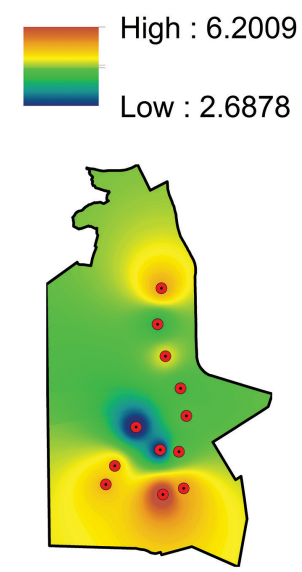

NP
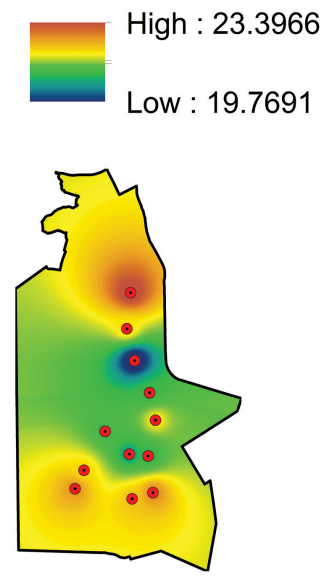

\section{B.Diversity}

High : 3.4682

Low : 2.8347

Figure 5. Interpolated surfaces of acoustic indices and bird indices derived from point counts in Santa Rosa National Park, Costa Rica.

AEI: Acoustic Evenness Index, ADI: Acoustic Diversity Index, ACl: Acoustic Complexity Index, BIO: Bioacoustic Index, NDSI: Normalized Difference Soundscape Index, TE: Total Entropy, MAE: Median Amplitude Envelope, NP: Number of Peaks, B.Richness: Bird Richness, B.Evenness: Bird Evenness, B.Abundance: Bird Abundance, B.Diversity: Bird Diversity. Warm and cold colors indicate higher and lower values of the interpolated index, respectively. 
Table 2. Generalized linear models showing the relationship between acoustic or bird point count indices with habitat and spatial variables in Santa Rosa National Park, Costa Rica. Only the best model and models with a delta AIC less than 2 are shown for each acoustic or bird point count derived index.

\begin{tabular}{|c|c|c|c|c|c|c|c|c|}
\hline \multirow[t]{2}{*}{ Model } & \multicolumn{3}{|c|}{ Coefficients } & \multirow[t]{2}{*}{ DF } & \multirow[t]{2}{*}{ Residual } & \multirow[t]{2}{*}{ Null dev } & \multirow[t]{2}{*}{ Res dev } & \multirow[t]{2}{*}{$\Delta \mathrm{AIC}$} \\
\hline & Intercept & Var 1 & Var 2 & & & & & \\
\hline AEI CANOPY + NUMP & 1.1889 & -0.0301 & 0.0643 & 9 & 7 & 0.5692 & 0.1763 & 0 \\
\hline AEI NUMP & -1.6889 & 0.0645 & & 9 & 8 & 0.5692 & 0.3486 & 0.85 \\
\hline ADI NUMP & 0.9021 & -0.0277 & & 9 & 8 & 0.0965 & 0.0596 & 0 \\
\hline ADI $\sim$ CANOPY + NUMP & -0.1237 & 0.0107 & -0.0278 & 9 & 7 & 0.0965 & 0.0385 & 1.63 \\
\hline $\mathrm{ACl} \sim \mathrm{CANOPY}$ & 6.9039 & -0.0028 & & 9 & 8 & 0.0024 & 0.0009 & 0 \\
\hline $\mathrm{BIO} \sim \mathrm{CANOPY}$ & 5.8881 & -0.0479 & & 9 & 8 & 0.7538 & 0.2702 & 0 \\
\hline NDSI NTREES & -0.4770 & 0.0009 & & 9 & 8 & 0.0223 & 0.0069 & 0 \\
\hline NDSI NTREES + NUMP & -0.5569 & 0.0010 & 0.0080 & 9 & 7 & 0.0223 & 0.0039 & 0.29 \\
\hline TE NUMP & -0.0983 & -0.0069 & & 9 & 8 & 0.0066 & 0.0043 & 0 \\
\hline TE NTREES & -0.2038 & 0.0004 & & 9 & 8 & 0.0066 & 0.0044 & 0.31 \\
\hline TE NTREES + NUMP & -0.1454 & 0.0003 & -0.0059 & 9 & 7 & 0.0066 & 0.0027 & 1.50 \\
\hline TE NTREES + MPE & -0.1665 & 0.0004 & 0.0000 & 9 & 7 & 0.0066 & 0.0028 & 1.87 \\
\hline MAE NUMP & -4.8727 & 0.0503 & & 9 & 8 & 0.3250 & 0.1882 & 0 \\
\hline MAE NTREES & -4.1353 & -0.0024 & & 9 & 8 & 0.3250 & 0.2223 & 1.67 \\
\hline NP CANOPY & 2.3474 & 0.0075 & & 9 & 8 & 0.0234 & 0.0133 & 0 \\
\hline NP $\sim \mathrm{CANOPY}+\mathrm{MPE}$ & 2.4490 & 0.0073 & 0.0000 & 9 & 7 & 0.0234 & 0.0075 & 0.28 \\
\hline NP $\sim \mathrm{CANOPY}+\mathrm{NUMP}$ & 2.4434 & 0.0074 & -0.0104 & 9 & 7 & 0.0234 & 0.0077 & 0.57 \\
\hline Bird diversity BASALAREA & 1.2760 & 0.0000 & & 9 & 8 & 0.0314 & 0.0219 & 0 \\
\hline Bird diversity NUMP & 1.2474 & -0.0107 & & 9 & 8 & 0.0314 & 0.0257 & 1.60 \\
\hline Bird evenness CANOPY & -0.3577 & 0.0026 & & 9 & 8 & 0.0066 & 0.0053 & 0 \\
\hline Bird evenness $~$ UNDERSTORY & -0.0881 & 0.0000 & & 9 & 8 & 0.0066 & 0.0054 & 0.17 \\
\hline Bird evenness NUMP & -0.0770 & -0.0032 & & 9 & 8 & 0.0066 & 0.0060 & 1.33 \\
\hline Bird evenness $~$ NTREES & -0.1162 & 0.0001 & & 9 & 8 & 0.0066 & 0.0064 & 1.90 \\
\hline Bird richness BASALAREA & 3.9567 & -0.0001 & & 9 & 8 & 0.2272 & 0.1119 & 0 \\
\hline Bird abundance $\sim$ CANOPY & 4.3947 & -0.0427 & & 9 & 8 & 0.5283 & 0.1658 & 0 \\
\hline Bird abundance $\sim$ CANOPY + MPAR & 5.5305 & -0.0525 & -0.0002 & 9 & 7 & 0.5283 & 0.1002 & 0.95 \\
\hline
\end{tabular}




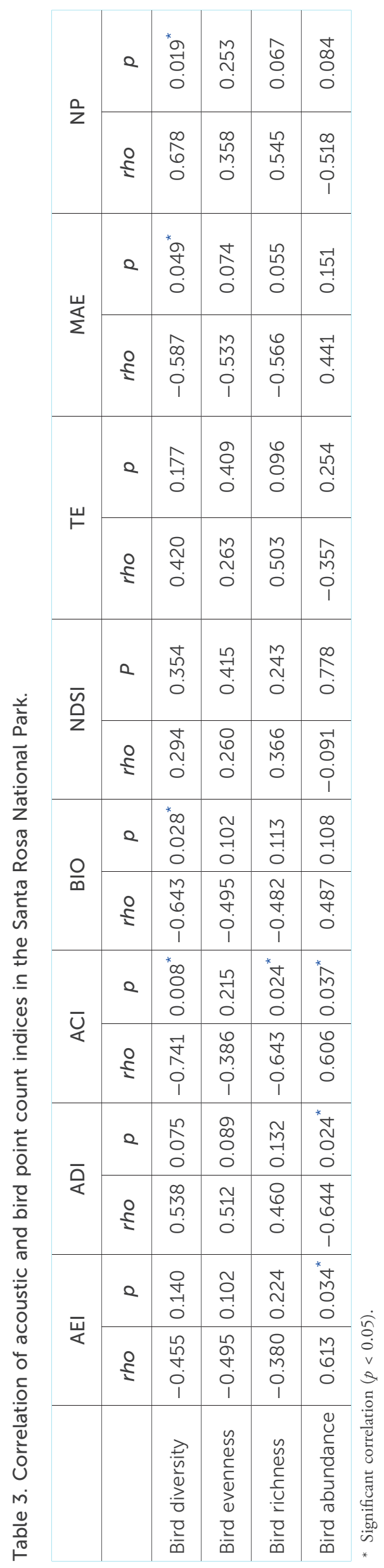




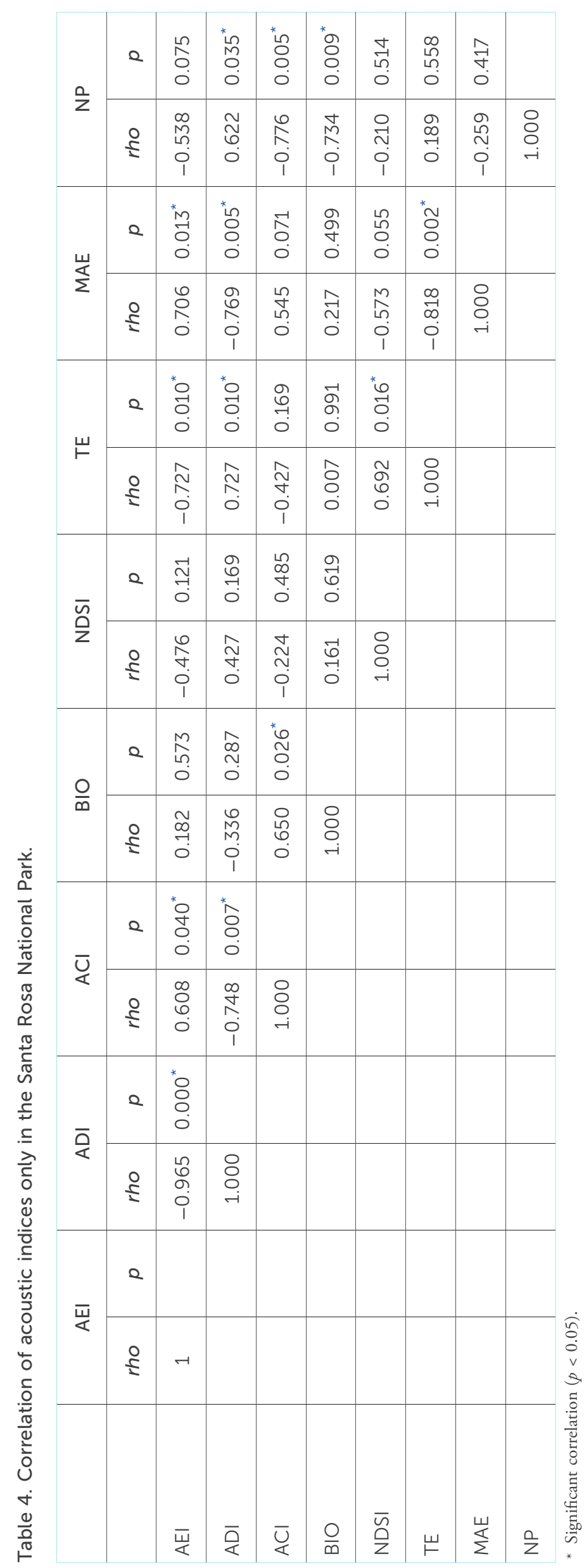


However, other authors have found that ACI strongly responded to cicadas (Duarte et al., 2015; Pieretti et al., 2015).

On the other hand, the AEI index showed a temporal pattern contrary to that of ADI, BIO and TE. This is expected because of what these indices represent, since the AEI is denoting acoustic evenness, while the other indices represent heterogeneity and entropy, thus representing extremes in the same spectrum. Regarding NDSI, the highest value, i.e., the highest proportion of biophony over antrophony, was found at $5 \mathrm{pm}$. This is consistent with the lowest intensity of human activity at the park, given that SRNP operates from 8 am to $4 \mathrm{pm}$.

The results of this study were partially consistent with other studies that compared acoustic data with bird data. Farina et al. (2011) and Pieretti et al. (2011) tested the ACI to infer bird community activity in a temperate forest in Italy and found the ACI index described the complexity of bird soundscapes. Towsey et al. (2014) found that acoustic indices such as Ht, Hs and ACI were useful indicators of bioacoustic activity and species diversity, using field data obtained from shrub areas of the Samford Ecological Research Institute in Australia. Machado et al. (2017) found the ADI was significantly correlated to the number of bird species in the savannas of Central Brazil. However, in a similar study conducted in southern China, Mammides et al. (2017) found that although no index showed a very strong correlation with species richness or diversity, three indices (the acoustic entropy, acoustic diversity and acoustic evenness indices) performed consistently better, showing moderate correlations.

In this study, most indices related to acoustic diversity or entropy behaved as expected, showing a higher diversity or entropy in areas where bird diversity or richness was higher as well. However, bird diversity showed a positive statistical relationship only to the number of peaks. But the very surprising and unexpected find was the positive and significant correlation between ACI and bird abundance derived from point counts, and even more the negative correlation between ACI and bird diversity or bird richness. A similar and unexpected pattern was found between BIO and bird indices, although no significant correlation was found in this case. Our expectations of a higher acoustic diversity, heterogeneity or complexity, and higher bird diversity in older and more preserved forests also were achieved, except for ACI and BIO. For instance, higher values of ACI, BIO, as well as bird abundance, were related to characteristics of younger forests.

$\mathrm{ACI}$ and $\mathrm{BIO}$ seem to be reflecting efficiently a high biological activity, but might not necessarily be the case of a more diverse or complex bird community in this particular area. Younger forests usually present a high environmental heterogeneity both horizontally and vertically (MacArthur and MacArthur, 1961), providing a variety of niches for some opportunistic species, or a mixture of species with different life history characteristics. Some authors have stated that forests at earlier stages of succession maintain a greater dynamic of food production than mature forests (Flores and Dezzeo, 2005), which may gather several guilds of species (Almazán-Núnez et al., 2009). This strong acoustic activity might be an indication of an ongoing acoustic competition in a less established bird community. According to the acoustic niche hypothesis, the soundscape is a limited resource where individuals must compete to communicate effectively; resulting in sound niches where the soundscape is spatially and temporally divided (Krause, 1987; Pijanowski et al., 2011). In addition, younger forests might be dominated by some bird species with a particular intense vocalizing behavior, which subsequently dominate the acoustic spectrum and influence acoustic indices.

Other factors might affect acoustic indices, such as ACI and BIO. For example, there is a strong acoustic activity from other animal groups in tropical forests (mainly insects such as cicadas and crickets, as well as frogs), which play a significant role in the bioacoustic activity. According to Sueur et al. (2014) single species producing a noise like sound, like some cicadas do, might return higher values for certain indices, such as NP, than several species producing pure tone sound; and this bias may also affect other indices. Although we removed all those recordings extremely affected by insects and frogs explosions, it is necessary to acknowledge and account for their common presence in tropical forests. 
NP was positively correlated to Bird Diversity and also related to characteristics of older forests (such as a higher percentage of canopy cover and a lower number of patches at the landscape level). NP is built by counting the number of major frequency peaks obtained on a mean spectrum. The index results from the assumption that spectral complexity of a sound can be assessed by the number of frequency bands occupied. It is indeed expected that a sound produced by $\mathrm{n}+\mathrm{k}$ species should contain more frequency peaks than a sound due to $n$ species only (Gasc et al., 2013b).

Furthermore, ADI, TE, Bird Diversity and Bird Evenness were also related to characteristics of older forests (higher percentage of canopy cover and lower number of patches at the landscape level). The composition and richness of animal species, as well as temporal and spatial stability, increases as a forest is established (Cook et al., 2005). On the other hand, a better established forest usually contains a larger evolutionary history, and also has a higher density of woody trees compared to shrubs, which could facilitate the propagation of the sounds by providing a landscape with less attenuating elements (Hayes, 2016). Although older forests presented a higher basal area of trees than younger forests, they presented half the amount of understory shrubs in the study area, resulting in a noticeable clearer understory. As a result, values of acoustic indices would be expected to increase in more established forest areas, where landscape properties and competition for acoustic niches would lead to a more biodiverse soundscape (Hayes, 2016). Other authors also postulated that acoustic production of a community or landscape will increase in diversity with different individuals and species vocalizing, so it would be expected that more diverse communities in terms of number of species and individuals, are concurrently more diverse acoustic communities (Sueur et al., 2014).

NDSI behaved somewhat differently than other indices, because vegetation and landscape variables associated to that index were representative of younger or intermediate forests. In the case of NDSI, other confounding factors might be considered, such as proximity to the main road allowing access to the station at SRNP. For example, site 12 was located on a well preserved and evergreen forest patch in the study area, but also was located next to the main road to access the park, and consequently subjected to a persistent level of anthropophony.

On the other hand, other authors recognized that a single index may not be sufficient to represent all the acoustic energy of a recording (Towsey et al., 2014). These authors postulate that although it is not possible to propose combinations of indexes applicable to all climates and environments, they recommend using weighted combinations of relevant indexes could provide more robust results than using single indexes. They proposed using a combination of indexes such as $\mathrm{Ht}$, spectral entropy $(\mathrm{Hs})$ and ACI. A variety of methods is most likely needed to thoroughly assess biodiversity on a site; however, given the efficacy of automated recording methods and results of the present study, a combination of indices such as ACI and NP might be considered to monitor long-term trends in abundance and diversity of birds in Costa Rican dry forests.

\section{Conclusions}

We conclude that acoustic indices have the potential to be used for monitoring trends in biodiversity in tropical ecosystems, although it might be worthwhile to adapt them to the special conditions in these environments. Acoustic indices have been created and applied mostly in temperate ecosystems, where bioacoustic activity can be referred to bird activity with adequate confidence. However, tropical ecosystems are rather more complex, consequently further investigation is necessary to assess influence of vocalizations from other animal groups, especially insects such as cicadas, on acoustic indices. Automatic procedures might be adapted to remove insect influence from recordings in specific studies. However, they are still part of the soundscape in tropical forests, although an unlikely target from a conservation perspective.

Future research might focus on analyzing the comparative value of combinations of indices to represent bird diversity in a locality. Further research is also needed on field sampling and resampling acoustic data schemes at appropriate minimum times in tropical forests. Given the importance of the vegetation structure in the estimated rates, it is necessary to replicate this study in humid forest types with different vegetation structure and microclimatic conditions, to validate the use of acoustic indices 
in such environments. Finally, to implement this method in tropical forests, appropriate and specific protocols must be designed for specific environmental conditions (for example forest type and climatic characteristics). Rigorous monitoring will allow comparisons of data in long-term studies focused on analyzing spatial-temporal trends in soundscapes related to changes in land use and climate. Furthermore, the general sampling of the soundscape could be complemented with specific studies on some species through the aid of the automated detection. For example, investigations on climate change effects, recordings and automated species detection can provides us with information on changes in species distribution, disappearance or appearance of species at different altitudinal or latitudinal ranges, which can be further complemented with a deeper analysis of vocalizing behavior in different environmental conditions or ranges.

\section{Supporting material}

Appendix 1. List of bird species observed in the Santa Rosa National Park, Guanacaste, Costa Rica. Status: R (Resident), M (Migratory), R-END (Resident endemic), RR (Reproductive Resident). (DOCX)

\section{Acknowledgements}

We thank to Christopher Vaughan for proof reading of the manuscript and recommendations.

\section{Funding sources}

Universidad Nacional, Costa Rica.

\section{Competing interests}

Mónica Retamosa Izaguirre, Oscar Ramírez-Alán and Jorge De la O Castro declare that they have no conflicts of interest.

\section{References}

Acevedo M., Corrada-Bravo C., Corrada-Bravo H., Villanueva-Rivera L., and Aide T. (2009). Automated classification of bird and amphibian calls using machine learning: A comparison of methods. Ecological Informatics. 4 (4): 206-214. https:// doi.org/10.1016/j.ecoinf.2009.06.005.

Aide T. M., Corrada-Bravo C., Campos-Cerqueira M., Milan C., Vega G., et al. (2013). Real-time bioacoustics monitoring and automated species identification. PeerJ. 1: e103. https://doi.org/10.7717/peerj.103.

Almazán-Núñez R., Puebla-Olivares F., and Almazán-Juárez Á. (2009). Diversidad de Aves en Bosques de Pino-Encino del Centro de Guerrero, México. Acta Zoológica Mexicana (N.S.). 25 (1): 123-142.

Armitage D. and Ober H. (2010). A comparison of supervised learning techniques in the classification of bat echolocation calls. Ecological Informatics. 5 (6): 465-473. https://doi.org/10.1016/j.ecoinf.2010.08.001.

Bardeli R., Wolff D., Kurth F., Koch M., Tauchert K., et al. (2010). Detecting bird sounds in a complex acoustic environment and application to bioacoustic monitoring. Pattern Recognition Letters. 31 (12): 1524-1534. https://doi.org/ 10.1016/j.patrec.2009.09.014.

Berg K., Brumfield R., and Apanius V. (2006). Phylogenetic and ecological determinants of the neotropical dawn chorus. Proceedings of the Royal Society B: Biological Sciences. 273 (1589): 999-1005. https://doi.org/10.1098/rspb.2005.3410.

Boelman N., Asner G., Hart P., and Martin R. (2007). Multi-trophic invasion resistance in Hawaii: Bioacoustics, field surveys, and airborne remote sensing. Ecological Applications. 17 (8): 2137-2144. https://doi.org/10.1890/07-0004.1.

Bolaños R. A., Watson V., and Tosi J. (2005). Mapa ecológico de Costa Rica (Zonas de Vida). Esc. 1:400,000. Heredia, Costa: Rica Centro Científico Tropical.

Calvo-Alvarado J., McLennan B., Sánchez-Azofeifa A., and Garvin T. (2009). Deforestation and forest restoration in Guanacaste, Costa Rica: Putting conservation policies in context. Forest Ecology and Management. 258 (6): 931-940. https://doi.org/10.1016/j.foreco.2008.10.035. 
Carvajal-Vanegas D. and Calvo-Alvarado J. (2013). Tasas de crecimiento, mortalidad y reclutamiento de vegetación en tres estadios sucesionales del bosque seco tropical, Parque Nacional Santa Rosa, Costa Rica. Revista Forestal Mesoamericana Kurú. 10 (25): 1-12. http://dx.doi.org/10.18845/rfmk.v10i25.1371.

Caycedo-Rosales P. C., Ruiz-Muñoz J. F., and Orozco-Alzate M. (2013). Reconocimiento automatizado de señales bioacústicas: Una revisión de métodos y aplicaciones. Ingeniería y Ciencia. 9 (18): 171-195.

Cook W., Yao J., Foster B., Holt R., and Patrick L. (2005). Secondary succession in an experimentally fragmented landscape: Community patterns across space and time. Ecology. 86 (5): 1267-1279. https://doi.org/10.1890/04-0320.

Cugler D. C., Medeiros C. B., and Toledo L. F. (2011). Managing animal sounds-some challenges and research directions. Proceedings V eScience Workshop-XXXI Brazilian Computer Society Conference 174. http://www.naturalhistory.com.br/ pdfs/Cugler\%20et\%20al\%202011\%20Managing\%20Animal\%20Sounds.pdf or https://scholar.google.com.br/citations? user $=\mathrm{a} 07 \mathrm{MBS} c A A A A J \& \mathrm{hl}=\mathrm{en}$.

Depraetere M., Pavoine S., Jiguet F., Gasc A., Duvail S., et al. (2012). Monitoring animal diversity using acoustic indices: Implementation in a temperate woodland. Ecological Indicators. 13 (1): 46-54. https://doi.org/10.1016/j.ecolind.2011.05.006.

Dickinson J., Zuckerberg B., and Bonter D. (2010). Citizen science as an ecological research tool: Challenges and benefits. Annual Review of Ecology, Evolution, and Systematics. 41 (1): 149-172. https://doi.org/10.1146/annurev-ecolsys-102209-144636.

Duarte M. H. L., Sousa-Lima R. S., Young R. J., Farina A., Vasconcelos M., et al. (2015). The impact of noise from open-cast mining on Atlantic forest biophony. Biological Conservation. 191 (2015): 623-631. https://doi.org/10.1016/j.biocon.2015.08.006.

ESRI (2016). ArcGIS Desktop: Release 10.5. Redlands, California, USA: Environmental Systems Research Institute.

Farina A., Pieretti N., and Piccioli L. (2011). The soundscape methodology for long-term bird monitoring: A Mediterranean Europe case-study. Ecological Informatics. 6 (6): 354-363. https://doi.org/10.1016/j.ecoinf.2011.07.004.

Farnsworth A. and Russell R. (2007). Monitoring flight calls of migrating birds from an oil platform in the northern Gulf of Mexico. Journal of Field Ornithology. 78 (3): 279-289. https://doi.org/10.1111/j.1557-9263.2007.00115.x.

Flores S. and Dezzeo N. (2005). Variaciones temporales en cantidad de semillas en el suelo y en lluvia de semillas en un gradiente bosque-sabana en la Gran Sabana, Venezuela. Interciencia. 30 (1): 39-43.

Gage S. H., Joo W., Kasten E. P., Fox J., and Biswas S. (2015). Acoustic observations in agricultural landscapes. In: The Ecology of Agricultural Landscapes: Long-Term Research on the Path to Sustainability, edited by Hamilton S. K., Doll J. E., and Robertson G. P. New York, USA: Oxford University Press. 360-377.

Gasc A., Sueur J., Jiguet F., Devictor V., Grandcolas P., et al. (2013a). Assessing biodiversity with sound: Do acoustic diversity indices reflect phylogenetic and functional diversities of bird communities? Ecological Indicators. 25: $279-287$. https://doi.org/10.1016/j.ecolind.2012.10.009.

Gasc A., Sueur J., Pavoine S., Pellens R., and Grandcolas P. (2013b). Biodiversity sampling using a global acoustic approach: Contrasting sites with microendemics in New Caledonia. PLoS ONE. 8 (5): e65311. https://doi.org/10.1371/journal. pone. 0065311 .

Gillespie T. W., Grijalva A., and Farris C. N. (2000). Diversity, composition, and structure of tropical dry forests in Central America. Plant Ecology. 147 (1): 37-47. https://doi.org/10.1023/A:1009848525399.

Graham B., Sandoval L., Dabelsteen T., and Mennill D. (2016). A test of the acoustic adaptation hypothesis in three types of tropical forest: Degradation of male and female Rufous-and-white Wren songs. Bioacoustics. 26 (1): 37-61. https://doi.org/ 10.1080/09524622.2016.1181574.

Han N., Muniandy S., and Dayou J. (2011). Acoustic classification of Australian anurans based on hybrid spectral-entropy approach. Applied Acoustics. 72 (9): 639-645. https://doi.org/10.1016/j.apacoust.2011.02.002.

Hayes L. (2016). The hills are alive with the sound of music: The interaction between soundscape and vegetation structure in a successional forest. Bachelor's thesis, Princeton University.

Henwood K. and Fabrick A. (1979). A quantitative analysis of the dawn chorus: Temporal selection for communicatory optimization. The American Naturalist. 114 (2): 260-274. https://doi.org/10.1086/283473.

Janzen D. (2000). Costa Rica’s Area de Conservación Guanacaste: A long march to survival through non-damaging biodevelopment. Biodiversity. 1 (2): 7-20. https://doi.org/10.1080/14888386.2000.9712501.

Janzen D. H. (2004). Ecology of dry-forest wildland insects in the Area de Conservación Guanacaste. In: Biodiversity Conservation in Costa Rica: Learning the Lessons in a Seasonal Dry Forest, edited by Frankie G. W., Mata A., and Vinson S. B. Berkeley and Los Angeles, California, USA: University of California Press. 80-96.

Kalacska M., Sanchez-Azofeifa G., Calvo-Alvarado J., Quesada M., Rivard B., et al. (2004). Species composition, similarity and diversity in three successional stages of a seasonally dry tropical forest. Forest Ecology and Management. 200 (1-3): 227247. https://doi.org/10.1016/j.foreco.2004.07.001.

Kasten E., Gage S., Fox J., and Joo W. (2012). The remote environmental assessment laboratory's acoustic library: An archive for studying soundscape ecology. Ecological Informatics. 12: 50-67. https://doi.org/10.1016/j.ecoinf.2012.08.001. 
Kindt R. (2018). BiodiversityR: GUI for Biodiversity, Suitability and Community Ecology Analysis. Nairobi: World Agroforestry Centre (ICRAF).

Klingbeil B. T. and Willig M. R. (2015). Bird biodiversity assessments in temperate forest: The value of point count versus acoustic monitoring protocols. PeerJ. 3: e973. https://doi.org/10.7717/peerj.973.

Krause B. (1987). Bioacoustics, habitat ambiance in ecological balance. Whole Earth Review. 57: 14-18.

Lee C., Han C., and Chuang C. (2008). Automatic classification of bird species from their sounds using two-dimensional cepstral coefficients. IEEE Transactions on Audio, Speech, and Language Processing. 16 (8): 1541-1550. https://doi.org/ 10.1109/TASL.2008.2005345.

Macarthur R. H. and Macarthur J. W. (1961). On bird species diversity. Ecology. 42 (3): 594-598. https://doi.org/10.2307/ 1932254.

Machado R. B., Aguiar L., and Jones G. (2017). Do acoustic indices reflect the characteristics of bird communities in the savannas of Central Brazil? Landscape and Urban Planning. 162: 36-43. https://doi.org/10.1016/j.landurbplan.2017.01.014.

Mammides C., Goodale E., Dayananda S. K., Kang L., and Chen J. (2017). Do acoustic indices correlate with bird diversity? Insights from two biodiverse regions in Yunnan Province, south China. Ecological Indicators. 82: 470-477. https://doi.org/ 10.1016/j.ecolind.2017.07.017.

Marsh D. and Trenham P. (2008). Current trends in plant and animal population monitoring. Conservation Biology. 22 (3): 647-655. https://doi.org/10.1111/j.1523-1739.2008.00927.x.

Mason R., Roe P., Towsey M., Zhang J., Gibson J., et al. (2008). Towards an acoustic environmental observatory. Fourth IEEE International Conference on eScience: IEEE Computer Society 135-142. https://doi.org/10.1109/eScience.2008.16.

Mennill D. and Vehrencamp S. (2008). Context-dependent functions of avian duets revealed by microphone-array recordings and multispeaker playback. Current Biology. 18 (17): 1314-1319. https://doi.org/10.1016/j.cub.2008.07.073.

Miles L., Newton A., DeFries R., Ravilious C., May I., et al. (2006). A global overview of the conservation status of tropical dry forests. Journal of Biogeography. 33 (3): 491-505. https://doi.org/10.1111/j.1365-2699.2005.01424.x.

Odom K. and Mennill D. (2010). A quantitative description of the vocalizations and vocal activity of the barred owl. The Condor. 112 (3): 549-560. https://doi.org/10.1525/cond.2010.090163.

Ospina O., Villanueva-Rivera L., Corrada-Bravo C., and Aide T. (2013). Variable response of anuran calling activity to daily precipitation and temperature: Implications for climate change. Ecosphere. 4 (4): 47. http://dx.doi.org/10.1890/ES1200258.1

Pielou E. C. (1984). The Interpretation of Ecological Data: A Primer on Classification and Ordination. USA: John Wiley \& Sons.

Pieretti N., Farina A., and Morri D. (2011). A new methodology to infer the singing activity of an avian community: The Acoustic Complexity Index (ACI). Ecological Indicators. 11 (3): 868-873. https://doi.org/10.1016/j.ecolind.2010.11.005.

Pieretti N., Duarte M. H. L., Sousa-Lima R. S., Rodrigues M., Young R. J., et al. (2015). Determining temporal sampling schemes for passive acoustic studies in different tropical ecosystems. Tropical Conservation Science. 8 (1): 215-234. https:// doi.org/10.1177/194008291500800117.

Pijanowski B. C., Villanueva-Rivera L. J., Dumyahn S. L., Farina A., Krause B. L., et al. (2011). Soundscape ecology: The science of sound in the landscape. BioScience. 61 (3): 203-216. https://doi.org/10.1525/bio.2011.61.3.6.

Porter J., Arzberger P., Braun H.-W., Bryant P., Gage S., et al. (2005). Wireless sensor networks for ecology. AIBS Bulletin. 55 (7): 561-572. https://doi.org/10.1641/0006-3568(2005)055[0561:WSNFE]2.0.CO;2.

Powers J., Becknell J., Irving J., and Pérez-Aviles D. (2009). Diversity and structure of regenerating tropical dry forests in Costa Rica: Geographic patterns and environmental drivers. Forest Ecology and Management. 258 (6): 959-970. https://doi. org/10.1016/j.foreco.2008.10.036.

R Development Core Team (2017). R: A Language and Environment for Statistical Computing. Vienna, Austria: R Foundation for Statistical Computing.

Rempel R. S., Kaukinen D., and Carr A. P. (2012). Patch Analyst and Patch Grid. Thunder Bay, Canada: Ontario Ministry of Natural Resources, Centre for Northern Forest Ecosystem Research.

Rodrigues A., Gasc A., Pavoine S., Grandcolas P., Gaucher P., et al. (2014). Temporal and spatial variability of animal sound within a neotropical forest. Ecological Informatics. 21: 133-143. https://doi.org/10.1016/j.ecoinf.2013.12.006.

Salas E., Ross Salazar E., and Arias A. (2012). Diagnóstico de áreas marinas protegidas y áreas marinas para la pesca responsable en el Pacífico costarricense. San José, Costa Rica: Fundación MarViva.

Shannon C. and Weaver W. (1964). The Mathematical Theory of Communication. Urbana, USA: University of Illinois Press.

Solano J. and Villalobos R. (2001). Aspectos fisiográficos aplicados a un bosquejo de regionalización geográfico climático de Costa Rica. Tópicos Meteorológicos y Oceanográficos. 8 (1): 26-39. 
Stanley C. Q., Walter M. H., Venkatraman M. X., and Wilkinson G. S. (2016). Insect noise avoidance in the dawn chorus of Neotropical birds. Animal Behaviour. 112: 255-265. https://doi.org/10.1016/j.anbehav.2015.12.003.

Stiles G. and Skutch A. (2007). Guía de aves de Costa Rica, 4th edition (illustration Garner D., translation Roselli, L.). Heredia, Costa Rica: Instituto Nacional de Biodiversidad.

Sueur J., Aubin T., and Simonis C. (2008a). Seewave, a free modular tool for sound analysis and synthesis. Bioacoustics. 18 (2): 213-226. https://doi.org/10.1080/09524622.2008.9753600.

Sueur J., Farina A., Gasc A., Pieretti N., and Pavoine S. (2014). Acoustic indices for biodiversity assessment and landscape investigation. Acta Acustica united with Acustica. 100 (4): 772-781. https://doi.org/10.3813/AAA.918757.

Sueur J., Pavoine S., Hamerlynck O., and Duvail S. (2008b). Rapid acoustic survey for biodiversity appraisal. PLoS ONE. 3 (12): e4065. https://doi.org/10.1371/journal.pone.0004065.

Towsey M., Wimmer J., Williamson I., and Roe P. (2014). The use of acoustic indices to determine avian species richness in audio-recordings of the environment. Ecological Informatics. 21: 110-119. https://doi.org/10.1016/j.ecoinf.2013.11.007.

Trigg L. (2015). Assessment of acoustic indices for monitoring phylogenetic and temporal patterns of biodiversity in tropical forests. PhD thesis, Imperial College London.

Villanueva-Rivera L. J. and Pijanowski B. C. (2018). Package "soundecology." License: GPL-3. Available at: http://jvilla nueva.github.io/soundecology/. 